\title{
The risk factors of early recurrence after hepatectomy in hepatocellular carcinoma
}

\author{
Soon-Keun Kwon, Sung-Su Yun, Hong-Jin Kim, Dong-Shik Lee \\ Department of Surgery, Yeungnam University College of Medicine, Daegu, Korea
}

\begin{abstract}
Purpose: Early recurrence after hepatectomy is a well-known poor prognostic factor in patients with hepatocellular carcinoma. This study was undertaken to identify the risk factors of early recurrence in patients with hepatocellular carcinoma after hepatectomy.

Methods: One hundred and sixty-seven patients that underwent hepatectomy for hepatocellular carcinoma from January 2005 to December 2010 were enrolled. The numbers of patients with or without early recurrence group were 40 and 127, respectively. Clinico-pathologic factors were retrospectively analyzed.

Results: Potential risk factors were classified as host, tumor, or surgical factors. Of the host factors examined, lobular hepatitis activity was found to be a significant risk factor of early recurrence, and of the tumor factors, infiltrative type of gross appearance, level of preoperative AFP and worst Edmondson-Steiner grade were significant.

Conclusion: The present study shows that an infiltrative gross appearance, a high preoperative AFP level, high lobular hepatitis activity, and a poor Edmondson-Steiner grade are independent risk factors of early recurrence. Accordingly, patients with these risk factors should be followed closely after hepatectomy.

[Ann Surg Treat Res 2014;86(6):283-288]
\end{abstract}

Key Words: Hepatocellular carcinoma, Recurrence, Hepatectomy

\section{INTRODUCTION}

Hepatic resection is a curative treatment is performed preferentially for hepatocellular carcinoma (HCC) patients with a well-preserved liver function. Overall survival rates have been reported to depend on several factors, such as, tumor size, treatment modality, degree of cirrhosis, and portal hypertension, and 5-year survival after hepatic resection has been reported to be $25 \%-74 \%$, but as high as $93 \%$ among selected patients [1].

Intrahepatic recurrence occurs in $70 \%-80 \%$ of patients within 5 years of surgery, and is known to be the strongest risk factor of poor survival after surgical treatment [1-5]. This recurrence can be divided into early and late recurrence according to time elapsed between surgery and the recurrence, and early recurrence (ER) is a well-known independent prognostic factor in HCC patients that have undergone hepatic resection [5-7].

This study was performed to identify the risk factors of ER after hepatectomy in patients with HCC.

\section{METHODS}

This retrospective study was conducted on 167 patients that underwent hepatic resection for histopathologically diagnosed HCC from January 1, 2005 to December 30, 2010. Subjects were divided into two groups; those that developed intrahepatic recurrence within one year of hepatic resection were allocated to the ER group $(n=40)$ and the others were allocated to the nonearly recurrence (NER) group $(\mathrm{n}=127)$. The NER group consisted of 44 patients who developed recurrence more than
Received February 3, 2014, Reviewed February 6, 2014, Accepted February 25, 2014

Corresponding Author: Dong-Shik Lee Department of Surgery, Yeungnam University College of Medicine, 170 Hyeonchung-ro, Nam-gu, Daegu 705-717, Korea

Tel: +82-53-620-3580, Fax: +82-53-624-1213

E-mail:dslee9@ynu.ac.kr
Copyright (c) 2014, the Korean Surgical Society

(c) Annals of Surgical Treatment and Research is an Open Access Journal. All articles are distributed under the terms of the Creative Commons Attribution NonCommercial License (http://creativecommons.org/licenses/by-nc/3.0/) which permits unrestricted non-commercial use, distribution, and reproduction in any medium, provided the original work is properly cited. 
one year later and 83 patients that did not develop recurrence during follow-up; the mean follow-up period was 39.9 months.

Intrahepatic recurrence was determined using blood test results, such as, serum AFP level, PIVKA-II, and abdominal ultrasonography and CT or MRI findings, and when necessary was confirmed by angiography. Potential risk factors of recurrence were classified as host, tumor, or surgical factors.

All histopathologic findings are described according to the guidelines issued by The Korean Liver Cancer Study Group. In patients with more than two tumors, the tumor with the poorest Edmondson-Steiner (E-S) grade was taken to be representative and when tumor had the same E-S grade, the largest tumor was chosen. In addition, hepatitis severity was described using grade of hepatitis activity and stage of cirrhosis. And, grade of hepatitis activity were evaluated using lobular and porto-periportal activities, as described by the guideline issued by the Korean Society of Pathologists [8,9].

Results were expressed as a mean \pm standard deviation. Differences between group discontinuous variables were analyzed using the chi-square test and Fisher exact test, as appropriate. Multivariate analysis was performed using logistic regression analysis to identify variables independently associated with recurrence from among those found to be significant by univariate analysis. Survival rates were analyzed by using Kaplan-Meier curves and the log rank test was used to compare group survival rates. The analysis was performed using IBM SPSS ver. 19.0 (IBM Co., Armonk, NY, USA) using a significance level of $5 \%(\mathrm{P}<0.05)$.

\section{RESULTS}

\section{Host factors}

Of the host factors, a high grade of lobular activity was more prevalent in the ER group than in the NER group $(10.0 \%$ vs. $0.8 \%$, $\mathrm{P}=0.012$.

However, no significant difference was found for ages, sex, serum albumin levels, presences of hepatitis B and C, portoperiportal activity of the hepatitis and the stages of cirrhosis between ER and NER group (Table 1).

\section{Tumor factors}

Of the tumor factors, gross appearance and sizes of tumors, E-S grade, preoperative AFP level, presence of capsules, portal vein invasion, bile duct invasion, hepatic vein invasion, microvascular invasion, and preoperative spontaneous tumor rupture were significantly related with ER. However, no significant association was observed between tumor multiplicity, tumor necrosis, capsular infiltration, septal formation, or perineural invasion and ER.

Regarding gross findings, the expanding nodular tumor type was more prevalent in the NER group $(P=0.001)$ than in the ER
Table 1. Comparison of clinicopathologic host factors in the early recurrence group (ER) and the nonearly recurrence group (NER)

\begin{tabular}{|c|c|c|c|}
\hline Variable & $\begin{array}{c}\text { ER } \\
(n=40)\end{array}$ & $\begin{array}{c}\text { NER } \\
(n=127)\end{array}$ & P-value \\
\hline Age $(y r)$ & & & 0.077 \\
\hline$>55$ & $15(37.5)$ & $68(53.5)$ & \\
\hline$\leq 55$ & $25(62.5)$ & $59(46.5)$ & \\
\hline Gender & & & 0.463 \\
\hline Male & $31(77.5)$ & $105(82.7)$ & \\
\hline Female & $9(22.5)$ & $22(17.3)$ & \\
\hline Albumin (g/dL) & & & 0.019 \\
\hline$>3.7$ & $22(55.0)$ & $94(74.6)$ & \\
\hline$\leq 3.7$ & $18(45.0)$ & $32(25.4)$ & \\
\hline Bilirubin (mg/dL) & & & 0.218 \\
\hline$>1.4$ & $6(15.0)$ & $10(7.9)$ & \\
\hline$\leq 1.4$ & $34(85.0)$ & $117(92.1)$ & \\
\hline AST (IU/dL) & & & 0.210 \\
\hline$>50$ & $12(30.0)$ & $26(20.5)$ & \\
\hline$\leq 50$ & $28(70.0)$ & $101(79.5)$ & \\
\hline ALT (IU/dL) & & & 0.700 \\
\hline$>5$ & $9(22.5)$ & $25(19.7)$ & \\
\hline$\leq 50$ & $31(77.5)$ & $102(80.3)$ & \\
\hline $\mathrm{R} 15^{\mathrm{a})}$ & & & 0.867 \\
\hline$>10 \%$ & $23(59.0)$ & $75(60.5)$ & \\
\hline$\leq 10 \%$ & $16(41.0)$ & $49(39.5)$ & \\
\hline Serum HBsAg & & & 0.081 \\
\hline Positive & $32(80.0)$ & $83(65.4)$ & \\
\hline Negative & $8(20.0)$ & $44(34.6)$ & \\
\hline Serum anti-HCV & & & 0.464 \\
\hline Positive & $4(10.0)$ & $7(5.6)$ & \\
\hline Negative & $36(90.0)$ & $119(94.4)$ & \\
\hline \multicolumn{4}{|l|}{ Grade of hepatitis activity } \\
\hline Lobular activity & & & 0.012 \\
\hline $3-4$ & $4(10.0)$ & $1(0.8)$ & \\
\hline $0-2$ & $36(90.0)$ & $125(99.2)$ & \\
\hline Porto-periportal activity & & & 0.481 \\
\hline $3-4$ & $12(30.0)$ & $31(24.4)$ & \\
\hline $0-2$ & $28(70.0)$ & $96(75.6)$ & \\
\hline Stage of cirrhosis & & & 0.416 \\
\hline $3-4$ & $33(82.5)$ & $97(76.4)$ & \\
\hline $0-2$ & $7(17.5)$ & $30(23.6)$ & \\
\hline
\end{tabular}

Values are presented as number (\%).

$\mathrm{R} 15$, indocyanine green dye retention rate at 15 minutes.

${ }^{a)}$ Data was unavailable for 4 patients ( 1 in ER, 3 in NER).

group. In contrast, infiltrative type was more prevalent in the ER group $(P<0.01)$. No significant intergroup differences were observed for the vaguely nodular type, multinodular confluent type, or nodular type with perinodular extension.

E-S grades were classified a worst and major as described by the guidelines issued by the Korean Liver Cancer Study Group. The worst grade was more significantly prevalent than the major grade in the ER group $(\mathrm{P}=0.031$ vs. $\mathrm{P}=0.007$ ) (Table 2). 
Table 2. Comparison of clinicopathologic tumor factors in the early recurrence group (ER) and the nonearly recurrence group (NER)

\begin{tabular}{|c|c|c|c|}
\hline Variable & $\begin{array}{c}\text { ER } \\
(n=40)\end{array}$ & $\begin{array}{c}\text { NER } \\
(\mathrm{n}=127)\end{array}$ & P-value \\
\hline \multicolumn{4}{|l|}{ Gross appearance } \\
\hline Vaguely nodular & $0(0)$ & $6(4.7)$ & 0.337 \\
\hline Expending nodular & $12(30.0)$ & $75(59.1)$ & 0.001 \\
\hline Multinodular confluent & $1(2.5)$ & $9(7.1)$ & 0.286 \\
\hline $\begin{array}{l}\text { Nodular with perinodular } \\
\text { extension }\end{array}$ & $12(30.0)$ & $34(26.8)$ & 0.690 \\
\hline Infiltrative & $14(35.0)$ & $3(2.4)$ & $<0.01$ \\
\hline Tumor size $(\mathrm{cm})$ & & & $<0.01$ \\
\hline$>5$ & $18(45.0)$ & $15(11.8)$ & \\
\hline$\leq 5$ & $22(55.0)$ & $112(88.2)$ & \\
\hline Multiplicity & & & 0.151 \\
\hline Uninodular & $30(76.9)$ & $109(86.5)$ & \\
\hline Multinodular $(\geq 2)$ & $9(23.1)$ & $17(13.5)$ & \\
\hline $\begin{array}{l}\text { Major Edmondson-Steiner } \\
\text { grade }^{\text {a) }}\end{array}$ & & & 0.031 \\
\hline $3-4$ & $11(28.2)$ & $15(13.2)$ & \\
\hline $0-2$ & $28(71.8)$ & $99(86.8)$ & \\
\hline $\begin{array}{l}\text { Worst Edmondson-Steiner } \\
\text { grade }^{\text {a) }}\end{array}$ & & & 0.007 \\
\hline $3-4$ & $34(87.2)$ & $73(64)$ & \\
\hline $0-2$ & $5(12.8)$ & $41(36)$ & \\
\hline Preoperative AFP (ng/mL) & & & $<0.01$ \\
\hline$>1,000$ & $15(37.5)$ & $6(4.8)$ & \\
\hline$\leq 1,000$ & $25(62.5)$ & $119(95.2)$ & \\
\hline Tumor necrosis & & & 0.362 \\
\hline Complete & $2(5.0)$ & $14(11.1)$ & \\
\hline Partial and non & $38(95)$ & $112(88.9)$ & \\
\hline Capsule formation ${ }^{\text {b) }}$ & & & $<0.01$ \\
\hline Yes & $27(69.2)$ & $112(91.8)$ & \\
\hline No & $12(30.8)$ & $10(8.2)$ & \\
\hline Capsular infiltration ${ }^{c)}$ & & & 0.280 \\
\hline Present & $23(74.2)$ & $76(63.9)$ & \\
\hline Absent & $8(25.8)$ & $43(36.1)$ & \\
\hline Septum formation ${ }^{\mathrm{d})}$ & & & 0.512 \\
\hline Present & $29(82.9)$ & $87(77.7)$ & \\
\hline Absent & $6(17.1)$ & $25(22.3)$ & \\
\hline Hepatic capsular invasion ${ }^{\mathrm{e})}$ & & & $<0.01$ \\
\hline Present & $16(41.0)$ & $18(14.3)$ & \\
\hline Absent & $23(59.0)$ & $108(85.7)$ & \\
\hline Portal vein invasion & & & $<0.01$ \\
\hline Present & $16(40.0)$ & $7(5.5)$ & \\
\hline Absent & $24(60.0)$ & $120(94.5)$ & \\
\hline Bile duct invasion & & & 0.043 \\
\hline Present & $3(7.5)$ & $1(0.8)$ & \\
\hline Absent & $37(92.5)$ & $126(99.2)$ & \\
\hline Hepatic vein invasion ${ }^{f}$ & & & $<0.01$ \\
\hline Present & $11(28.2)$ & $4(3.1)$ & \\
\hline Absent & $28(71.8)$ & $123(96.9)$ & \\
\hline
\end{tabular}

\section{Surgical factors}

Extent of liver resection (minor vs, major), anatomical resection, intraoperative blood transfusion, tumor infiltration
Table 2. Continued

\begin{tabular}{|c|c|c|c|}
\hline Variable & $\begin{array}{c}\text { ER } \\
(n=40)\end{array}$ & $\begin{array}{c}\text { NER } \\
(\mathrm{n}=127)\end{array}$ & P-value \\
\hline Microvascular invasion & & & $<0.01$ \\
\hline Present & $24(60.0)$ & $30(23.6)$ & \\
\hline Absent & $13(40.0)$ & $97(76.4)$ & \\
\hline Perineural invasion ${ }^{\mathrm{g}}$ & & & 0.054 \\
\hline Present & $2(5.3)$ & $0(0)$ & \\
\hline Absent & $36(94.7)$ & $124(100)$ & \\
\hline Satellite nodules ${ }^{\text {h) }}$ & & & $<0.01$ \\
\hline Present & $18(46.2)$ & $17(13.5)$ & \\
\hline Absent & $21(53.8)$ & $109(86.5)$ & \\
\hline $\begin{array}{l}\text { Preoperative spontaneous } \\
\text { rupture of tumor }\end{array}$ & & & 0.013 \\
\hline Yes & $6(15.0)$ & $4(3.1)$ & \\
\hline No & $34(85.0)$ & $123(96.9)$ & \\
\hline
\end{tabular}

Values are presented as number (\%).

${ }^{a}$ Data was unavailable for 14 patients due to total tumor necrosis.

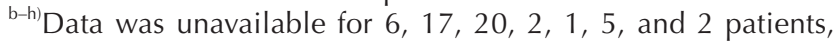
respectively.

Table 3. Comparison of clinicopathologic surgical factors with in thearly recurrence group (ER) and the nonearly recurrence group (NER)

\begin{tabular}{lrrr}
\hline \multicolumn{1}{c}{ Variable } & $\begin{array}{c}\text { ER } \\
(\mathrm{n}=40)\end{array}$ & $\begin{array}{c}\text { NER } \\
(\mathrm{n}=127)\end{array}$ & P-value \\
\hline $\begin{array}{l}\text { Extent of liver resection } \\
\text { Major resection }{ }^{\text {a) }}\end{array}$ & $15(37.5)$ & $33(26.0)$ & \\
$\quad \begin{array}{l}\text { Minor resection } \\
\text { Anatomic resection }\end{array}$ & $25(62.5)$ & $94(74.0)$ & \\
$\quad$ Anatomic & $33(82.5)$ & $88(69.3)$ & \\
$\quad$ Nonanatomic & $7(17.5)$ & $39(30.7)$ & \\
Intraoperative transfusion & & & 0.103 \\
$\quad$ Yes & $17(42.5)$ & $38(29.9)$ & \\
$\quad$ No & $23(57.5)$ & $89(70.1)$ & \\
Resection margin & $9(22.5)$ & $20(15.7)$ & \\
Involvement & $31(77.5)$ & $107(84.3)$ & \\
$\quad$ Not involvement & & & 0.326 \\
Preoperative TACE & $23(59.0)$ & $80(63.5)$ & \\
$\quad$ Yes & $16(41.0)$ & $46(36.5)$ & \\
No & & & \\
\hline
\end{tabular}

Values are presented as number (\%).

TACE, transarterial chemoembolization.

${ }^{\text {a) } M o r e ~ t h a n ~ t h r e e ~ s e g m e n t s ~ w e r e ~ r e s e c t e d . ~}$

of resection margin, and preoperative transarterial chemoembolization were not found to be significantly related to ER (Table 3).

\section{Independent risk factors}

Multivariate regression analysis showed that an infiltrative type, a higher preoperative AFP, a higher lobular activity, and a poor E-S grade in the worst part of tumors were independent risk factors of ER (Table 4). 
Table 4. Multivariate analysis of clinicopathologic factors of early recurrence after hepatectomy

\begin{tabular}{lclc}
\hline \multicolumn{1}{c}{ Variable } & Odd ratio & \multicolumn{1}{c}{$95 \% \mathrm{Cl}$} & P-value \\
\hline High AFP $(\mathrm{ng} / \mathrm{mL}), \geq 1,000$ & 14.242 & $3.943-51.443$ & $<0.01$ \\
Infiltrative type & 13.139 & $3.060-56.416$ & 0.001 \\
High lobular activity, 3-4 & 19.515 & $1.405-271.115$ & 0.027 \\
Worst E-S grade, 3-4 & 4.061 & $1.013-16.271$ & 0.048 \\
\hline Cl, confidence interval; E-S grade, Edmondson-Steiner grade.
\end{tabular}

\section{Overall survival rates}

Survival rates of 1 - and 3-year were $60.0 \%$ and $17.5 \%$ in ER group and $90.0 \%$ and $74.8 \%$ in NER group, which showed significant differences between groups, respectively $(\mathrm{P}<0.01)$ (Fig. 1).

\section{DISCUSSION}

Intrahepatic recurrence often occurs in HCC patients after hepatic resection, and can be divided into intrahepatic metastasis caused by the primary tumor and newly developed multicentric occurrence caused by carcinogenesis in the remnant liver after surgery $[3,4,10]$. The risk factors of recurrence in the patients with HCC also can be classified as tumor, host, and surgical factors. Intrahepatic metastasis and multicentric occurrence are referred to as tumor and host factors, respectively. Furthermore, when intrahepatic recurrence is divided into early and late recurrence about a cutoff of one or two years, ER appears to be caused by intrahepatic metastasis related to tumor factors and late recurrence to be caused by multicentric occurrence related to host factors. ER is known to be a poor prognostic factor in HCC patients after hepatic resection [4-6,11]. In the present study, ER was defined as recurrence within one year of resection.

Several studies have concluded that tumor gross appearance of tumor is prognostically important [12-14]. In the case of nodular HCC, the tumor capsule acts as a barrier and prevents tumor cells from spreading, but in case of infiltrative HCC cells can infiltrate peritumoral tissues. Furthermore, the unclear boundary in cases of infiltrative HCC makes the disease difficult to diagnose in the early stage by imaging [15-19]. In the present study, an infiltrative gross appearance was found to be an important risk factor of ER by univariate and multivariate analyses. In addition, $88 \%$ of patients with infiltrative HCC developed recurrence within one year, and for the 17 patients with infiltrative HCC, median disease-free survival and median overall survival were only three (1-26 months) and six months (2-49 months), respectively, and one and two year survival rate were only $23.5 \%$ and $11.7 \%$.

AFP has been used as the important tumor marker for the patients with HCC and is also known to be the important

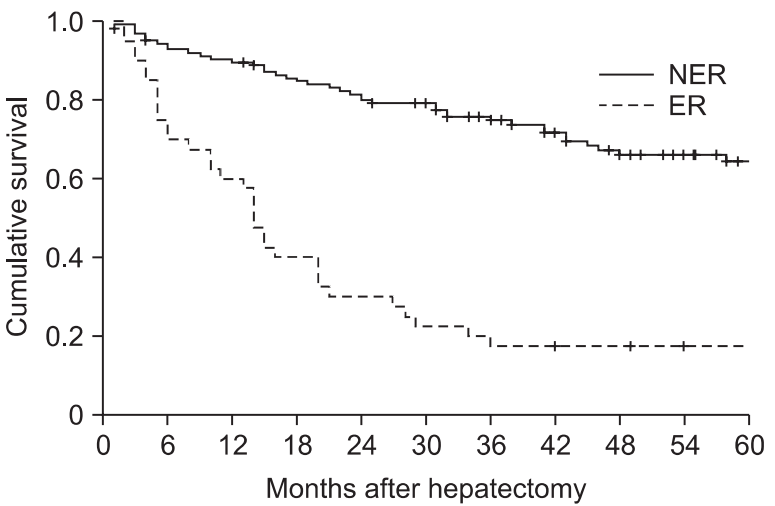

Fig. 1. Cumulative survivals in the early recurrence group (ER) and the nonearly recurrence group (NER).

prognostic factor [20,21], and a high AFP level has also been reported to be a risk factor of ER, but the cutoff values used by authors differ appreciably [12,20]. When Nomura et al. [22] classified AFP as $<20 \mathrm{ng} / \mathrm{mL}, 20-1,000 \mathrm{ng} / \mathrm{mL}$, or $>1,000$ $\mathrm{ng} / \mathrm{mL}$, patients with levels of $<20 \mathrm{ng} / \mathrm{mL}$ or $20-1000 \mathrm{ng} /$ $\mathrm{mL}$ showed similar survival rates, but patient with a level of $>1000 \mathrm{ng} / \mathrm{mL}$ had significantly lower survival rates than patients in either of the two lower classes. In the present study, multivariate analysis based on an AFP cutoff of $100 \mathrm{ng} /$ $\mathrm{mL}$ showed no significant difference, but analysis based on a cutoff of $1,000 \mathrm{ng} / \mathrm{mL}$ showed that AFP level is a significant, independent risk factor of $\mathrm{ER}$.

Histological grade (E-S) and its relation with ER are different depending on each reporter [23-25]. In this study, poor E-S grade acted as the important risk factor of ER. More than anything else, this study divide E-S grade into worst grade and major grade and the former showed the higher relation with ER than the latter. ( $\mathrm{P}=0.007$ vs. $\mathrm{P}=0.031$ ).

Hepatitis and cirrhosis are a host factor and known to be the risk factors of intrahepatic recurrence related to multicentric occurrence $[5,24]$. The present study shows that hepatitis $\mathrm{B}$, hepatitis $\mathrm{C}$, porto-periportal activity grade, and stage of cirrhosis are not related to ER. However, interestingly, a high lobular activity grade in hepatitis was found to be a risk factor of ER by univariate and multivariate analysis. That is to say, porto-periportal activity seems to affect developing HCC by the carcinogenesis following the occurrence of cirrhosis and its progress. On the other hand, severe lobular activity that shows extensive necrosis in lobules and con?uent necrosis from the central vein seems to be related to the development of HCC not only through the destruction of hepatic lobular structure from the portal-central septum but also accelerates the regeneration of hepatocytes and genetic alteration after vigorous and massive hepatocellular damage $[26,27]$. Therefore, the high lobular activity grade is supposed to be related to ER.

In conclusion, ER is an important prognostic factor in 
patients with HCC. The present study shows that the tumor factors, infiltrative gross appearance, a high AFP level $(>1,000$ $\mathrm{ng} / \mathrm{mL}$ ) and a poor E-S grade in the worst part of tumor, and the host factor, a high lobular activity grade, are independent risk factors of ER. Accordingly in the case of the patients with HCC with these risk factors, intensive follow-up is required for about one year after surgery.

\section{CONFLICTS OF INTEREST}

No potential conflict of interest relevant to this article was reported.

\section{REFERENCES}

1. Llovet JM, Burroughs A, Bruix J. Hepatocellular carcinoma. Lancet 2003;362:190717.

2. Bruix J, Sherman M; Practice Guidelines Committee, American Association for the Study of Liver Diseases. Management of hepatocellular carcinoma. Hepatology 2005:42:1208-36.

3. Poon RT, Fan ST, Lo CM, Liu CL, Wong J. Intrahepatic recurrence after curative resection of hepatocellular carcinoma: long-term results of treatment and prognostic factors. Ann Surg 1999:229:216-22.

4. Imamura H, Matsuyama Y, Tanaka E, Ohkubo T, Hasegawa K, Miyagawa S, et al. Risk factors contributing to early and late phase intrahepatic recurrence of hepatocellular carcinoma after hepatectomy. J Hepatol 2003;38:200-7.

5. Poon RT, Fan ST, Ng IO, Lo CM, Liu CL, Wong J. Different risk factors and prognosis for early and late intrahepatic recurrence after resection of hepatocellular carcinoma. Cancer 2000;89:500-7.

6. Shah SA, Greig PD, Gallinger S, Cattral MS, Dixon E, Kim RD, et al. Factors associated with early recurrence after resection for hepatocellular carcinoma and outcomes. J Am Coll Surg 2006;202:275-83.

7. Sakon M, Umeshita K, Nagano H, Eguchi $\mathrm{H}$, Kishimoto S, Miyamoto A, et al. Clinical significance of hepatic resection in hepatocellular carcinoma: analysis by disease-free survival curves. Arch Surg 2000;135:1456-9.

8. The Korean Liver Cancer Study Group. The general rules for the study of primary liver cancer. 2nd ed. Seoul: The Korean
Liver Cancer Study Group; 2004.

9. Park YN, Kim HG, Chon CY, Park JB, Sohn JH, Yang SH, et al. Histological grading and staging of chronic hepatitis standardized guideline proposed by the Korean study group for the pathology of digestive diseases. Korean J Pathol 1999; 33:337-46.

10. Tung-Ping Poon R, Fan ST, Wong J. Risk factors, prevention, and management of postoperative recurrence after resection of hepatocellular carcinoma. Ann Surg 2000;232:10-24.

11. Wu JC, Huang YH, Chau GY, Su CW, Lai CR, Lee PC, et al. Risk factors for early and late recurrence in hepatitis B-related hepatocellular carcinoma. J Hepatol 2009:51:890-7.

12. Choi GH, Han DH, Kim DH, Choi SB, Kang CM, Kim KS, et al. Outcome after curative resection for a huge $(>0 \mathrm{r}=10 \mathrm{~cm}$ ) hepatocellular carcinoma and prognostic significance of gross tumor classification. Am J Surg 2009;198:693-701.

13. Shimada M, Rikimaru T, Hamatsu T, Yamashita Y, Terashi T, Taguchi K, et al. The role of macroscopic classification in nodular-type hepatocellular carcinoma. Am J Surg 2001;182:177-82.

14. Hui AM, Takayama T, Sano K, Kubota K, Akahane M, Ohtomo K, et al. Predictive value of gross classification of hepatocellular carcinoma on recurrence and survival after hepatectomy. J Hepatol 2000;33:975-9.

15. Ng IO, Lai EC, Ng MM, Fan ST. Tumor encapsulation in hepatocellular carcinoma. A pathologic study of 189 cases.

\section{Cancer 1992;70:45-9.}

16. Sasaki $Y$, Imaoka $\mathrm{S}$, Ishiguro $\mathrm{S}, \mathrm{Nakano} \mathrm{H}$, Kasugai H, Fujita M, et al. Clinical features of small hepatocellular carcinomas as assessed by histologic grades. Surgery 1996;119:252-60.

17. Adachi E, Maeda T, Kajiyama K, Kinukawa N, Matsumata T, Sugimachi K, et al. Factors correlated with portal venous invasion by hepatocellular carcinoma: univariate and multivariate analyses of 232 resected cases without preoperative treatments. Cancer 1996;77:2022-31.

18. Demirjian A, Peng P, Geschwind JF, Cosgrove D, Schutz J, Kamel IR, et al. Infiltrating hepatocellular carcinoma: seeing the tree through the forest. J Gastrointest Surg 2011;15:2089-97.

19. Kneuertz PJ, Demirjian A, Firoozmand A, Corona-Villalobos C, Bhagat N, Herman J, et al. Diffuse infiltrative hepatocellular carcinoma: assessment of presentation, treatment, and outcomes. Ann Surg Oncol 2012;19:2897-907.

20. Li D1, Mallory T, Satomura S. AFP-L3: a new generation of tumor marker for hepatocellular carcinoma. Clin Chim Acta 2001;313:15-9.

21. Peng SY, Chen WJ, Lai PL, Jeng YM, Sheu JC, Hsu HC. High alpha-fetoprotein level correlates with high stage, early recurrence and poor prognosis of hepatocellular carcinoma: significance of hepatitis virus infection, age, p53 and betacatenin mutations. Int J Cancer 2004; 112:44-50.

22. Nomura F, Ohnishi K, Tanabe Y. Clinical features and prognosis of hepatocellular 
carcinoma with reference to serum alpha-fetoprotein levels: analysis of 606 patients. Cancer 1989;64:1700-7.

23. Kumada T, Nakano S, Takeda I, Sugiyama K, Osada T, Kiriyama S, et al. Patterns of recurrence after initial treatment in patients with small hepatocellular carcinoma. Hepatology 1997;25:87-92.

24. Li SL, Su M, Peng T, Xiao KY, Shang LM, $\mathrm{Xu} \mathrm{BH}$, et al. Clinicopathologic characteristics and prognoses for multicentric occurrence and intrahepatic metastasis in synchronous multinodular hepatocellular carcinoma patients. Asian Pac J Cancer Prev 2013;14:217-23.

25. Zhou YM, Yang JM, Li B, Yin ZF, Xu F, Wang B, et al. Risk factors for early recurrence of small hepatocellular carcinoma after curative resection. Hepatobiliary Pancreat Dis Int 2010;9:33-7.

26. Lee SH, Chung YH, Kim JA, Jin YJ, Park
WH, Choi JG, et al. Histological characteristics predisposing to development of hepatocellular carcinoma in patients with chronic hepatitis B. J Clin Pathol 2011;64:599-604.

27. Park BK, Park YN, Ahn SH, Lee KS, Chon CY, Moon YM, et al. Long-term outcome of chronic hepatitis B based on histological grade and stage. J Gastroenterol Hepatol 2007;22:383-8. 